\title{
The City of the Future Living Lab
}

\author{
Sauro Vicini*, Sara Bellini, and Alberto Sanna \\ Ospedale San Raffaele, Italy \\ (Received 9 January 2012; Accepted 22 June 2012; Published on line 1 September 2012) \\ *Corresponding author: vicini.sauro@hsr.it \\ DOI: 10.5875/ausmt.v2i3.134
}

Abstract: Living lab environments are known to establish and foster innovation, whilst supporting the transition from fundamental to applied research. San Raffaele Scientific Institute's City of the Future Living Lab in Milan has been created to observe an extended number of users interacting with a great number of services within a real city environment, as well as to engage them in a co-creation process that triggers and helps flourish tomorrow's e-Services.

Keywords: Living Lab; User-driven Open Innovation; Smart Cities; Intelligent Cities; Co-Creation

\section{Introduction}

This paper presents the case of San Raffaele Hospital's (OSR) City of the Future Living Lab in Milan, and its aim is to explore and discuss how the living lab concept can be extended to the understanding, studying and measuring of the interaction dynamics among users and Information and Communication Technology (ICT) based services, via a process called co-creation. This paper is explorative and elicited from ongoing development and practical implementation of the living lab in OSR.

At the same time, this paper focuses on delivering an overview of the City of the Future Living Lab as a realistic example of what is called Smart City or Intelligent City, or a context that is able to bring together users, ICT, researchers and businesses. Indeed, City of the Future Living Lab embodies a city, for it contains a university, laboratories, a hospital, offices, shops, a supermarket, post-offices, streets, parks, a shuttle and bus service, and so on. In such a setting, all actors of a city can be engaged to work together and co-create e-Services (or services that bring users and ICT together) designed around the end user in a virtual as well as real research environment and community.

\section{Smart City and Intelligent City}

In order to fully appreciate the relevance and the impact of City of the Future Living Lab, it is necessary to clarify what is meant by the terms Smart City and Intelligent City.

\section{Smart City}

There is an array of definitions used to explain what is meant by Smart City in contemporary literature. The following list of characteristics describing the necessary qualities for a city to be considered smart summarize the different views that have emerged from the study of literature, as eloquently described by Caragliu, Del Bo and Nijkamp, in their "Smart Cities in Europe" paper [1] :

- Smart City as a "wired city" that bases its source of growth on the connectivity obtained through its networked infrastructure [2, 3];

- Smart City as a "neo-liberal urban or business-oriented city", which are cities that attract new businesses therefore producing satisfactory socio-economic performance [4]; 
- Smart City as a city where the social inclusion of its urban residents within public services is crucial [5];

- Smart City as a city where high-tech and creative industries play a critical role in long-run urban growth (creative cultures known as soft infrastructure) [6];

- Smart City as a city that has made strong efforts in investing in social and relational capital, therefore creating a community that has successfully embraced technology and has learned to learn, adapt and innovate it [5];

- Smart City as a city that has invested its efforts in social and environmental sustainability, therefore successfully guaranteeing the safe and renewable use of natural heritage [1].

The report published by the Centre of Regional Science at Vienna University of Technology in 2007 [7] offers a holistic definition of Smart City which encompasses all of the above characteristics, which is that of a city which involves the cooperation of a multitude of fields of activities that include industry, education, participation, technical infrastructure, and various soft factors: "A Smart City is a city well performing in a forward-looking way in six characteristics (Smart Economy, Smart People, Smart Governance, Smart Mobility, Smart Environment, Smart Living), built on the smart combination of endowments and activities of self-decisive, independent and aware citizens [7]."

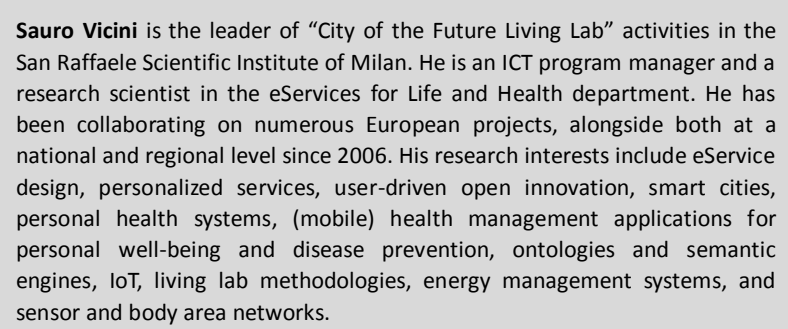

Sara Bellini is a design researcher with a long-lasting fascination for the understanding and fostering of innovation. Interested in all the elements that compose the innovation cycle, especially in user needs, behaviors and aspirations, and how they co-exist alongside science, technology and market evolutions. A strategic mind that greatly enjoys translating insights into actionable solutions, she has worked as a consultant for the most influential design consultancies and innovation firms, designing new products, services, experiences and strategies for sectors from healthcare to consumer goods.

Alberto Sanna graduated from Politecnico di Milano. He has been involved in the healthcare process of re-engineering projects in OSR since 1989. He has been in charge of several automation projects, designing and realizing robotic work cells for Patient- and Operator-safety critical processes. From 1992 to 1996 he was assigned to the Information Technology department, where his experience in robotics merged with process analysis, Information System analysis, design and implementation. Since 2002, he has been the head of the eServices for Life and Health Unit. He has published more than 60 articles in national and international magazines and holds three patents in the field of health innovative technologies.

\section{Intelligent City}

As Komninos clearly and precisely describes in his 2006 paper entitled "The Architecture of Intelligent Cities - Integrating human, collective and artificial intelligence to enhance knowledge and innovation" [8], at least four different meanings for Intelligent City can be found in contemporary literature:

- Intelligent City as a virtual reconstruction of cities or an equivalent of a digital city, which covers a wide range of electronic and digital applications related to digital spaces of communities and cities [9];

- Intelligent City as a Smart Community, which uses information technology "to transform life and work within its region in significant and fundamental, rather than incremental, ways" [10];

- Intelligent City as an Intelligent Space where "ICT disappears as it becomes embedded into physical objects and the spaces in which we live in and work. The ultimate vision is that this embedded technology provides us with intelligent and contextually relevant support, augmenting our lives and our experience of the physical world in a benign and non-intrusive manner" [11];

- Intelligent City as territories that bring innovation systems and ICTs within the same locality, combining the creativity of talented individuals that make up the population of the city, institutions that enhance learning and innovation, and virtual innovation spaces facilitating innovation and knowledge management [8].

At the end of his writings, Komninos concludes that Intelligent cities encompass all of the above definitions: "They represent environments that enable superior cognitive capabilities and creativity to be collectively constructed from combinations of individual cognitive skills and information systems that operate in the physical, institutional, and digital spaces of cities [12]."

Considering the literature presented in the above paragraphs, it quite clearly emerges that City of the Future Living Lab presents a unique context in which to execute ICT-based services user-driven innovation, for it is indeed a melting pot of all of the above features: a seamlessly interconnected ecosystem where products and environments interact among themselves across a number of ICT and Internet of Things (IOT)-enabled 
services, with the objective of not only empowering users, but also catalyzing the innovation process and bringing about positive social, economic and environmental change for governments, industries and citizens. A Smart or Intelligent City context for a living lab provides access not only to a wide set of users and stakeholders, but also to continuous stimuli since the scenarios available for analysis are variegated and concern all aspects of everyday life. Such a fertile setting enhances the process of innovation and helps to develop user-centered services that truly respond to user needs.

\section{City of the Future Living Lab}

San Raffaele Hospital has recently set up the City of the Future Living Lab, both a virtual as well as real research environment and community. The unit is managed and organized by "e-Services for Life and Health" (http://www.eservices4life.org), a department of OSR specialized in the application of Information Technology to health, with the aim of developing and delivering services for everyday life well-being as well as fostering innovation across numerous domains and disciplines. The Living Lab follows along the conceptual framework presented by ESOCE-Net in which user-driven innovation is fully integrated within the co-creation process of new services, products and societal infrastructures [13].

The City of the Future Living Lab is an ecosystem where a multitude of stakeholders and partners can work alongside each other sharing knowledge whilst interacting with a wide variety of ICTs, therefore creating a fertile ground for innovation and cross-disciplinary research and communication. The City of the Future Living Lab is a miniature version of a city (with a hotel, a hospital, stores and offices, a supermarket and a post-office, a shuttle and bus service as well as streets and parks) and articulates itself in numerous scenarios, which will be mentioned briefly at the end of this paper. Its aim is of understanding, studying and measuring the interaction dynamics among users and services offered.

The research methodology developed and implemented by the research team at City of the Future is based on the widely recognized living lab process [14]. The latter articulates itself around four concurrent phases: co-creation, exploration, experimentation, and evaluation (see Figure 1). Since this approach is an iterative and reflective one, a starting point is not defined and the process can be commenced at any stage of the innovation process.

\section{Co-Creation}

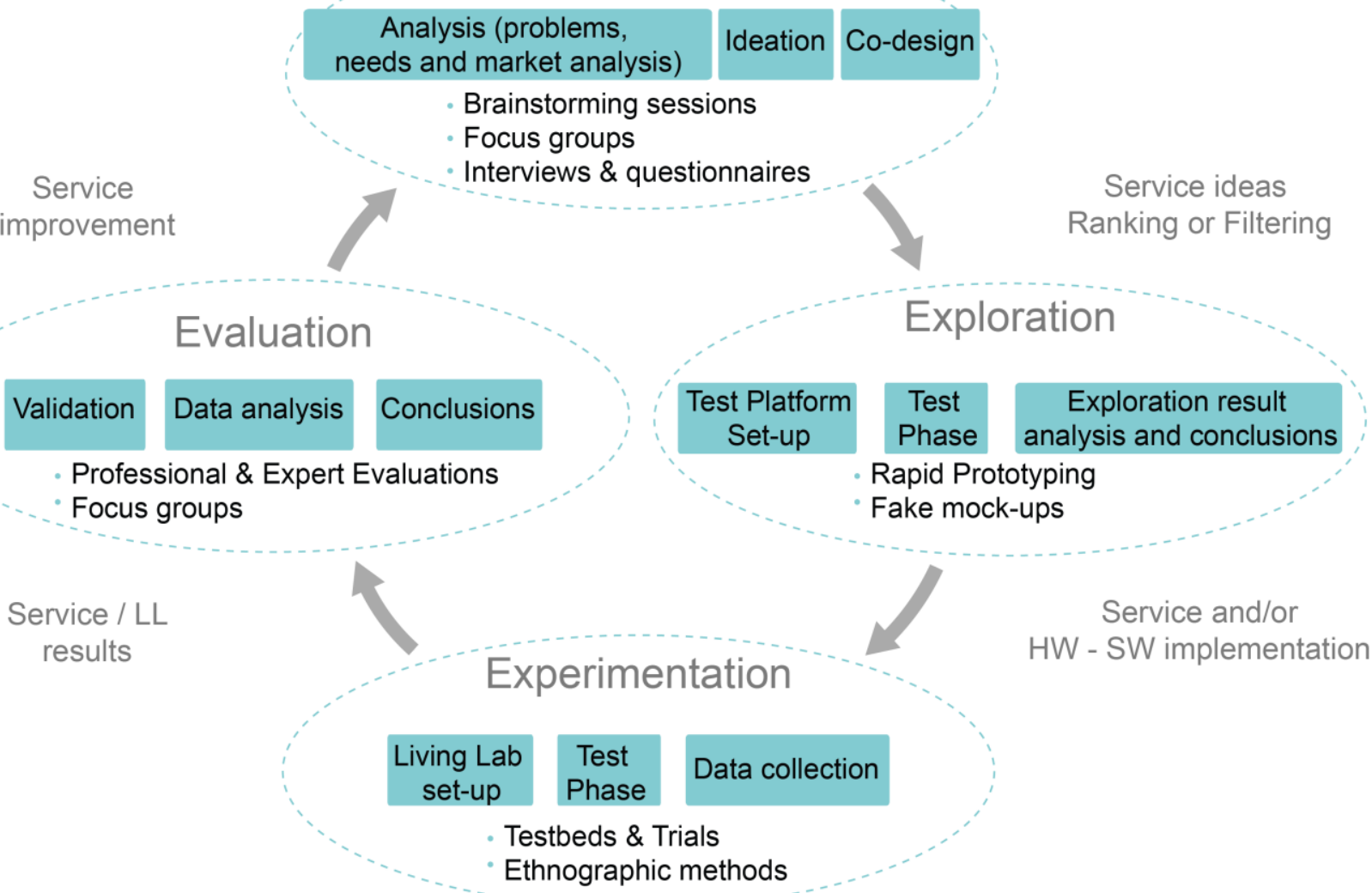

Figure 1. The Living Lab process. 
Living labs are innovation environments that focus on user communities embedded within "real life" situations and environments. The fundamental concept at the base of a living lab is to gain direct and unfiltered access to users' ideas, experiences, and knowledge, based on their daily needs and desire of feeling supported by products, services, or applications [15]. Users are directly involved in co-creating, exploring, experimenting and evaluating new ideas, concepts and technological artifacts related to loT applications and services. A living lab methodology based on co-creation [16] is an approach that focuses on making stakeholders and users constructive and active participants in the definition and construction of an artifact, be it a product, an interface, a service or an IoT, with the aim of improving and building value into these same artifacts. In the case of City of the Future Living Lab, users include patients and their families, the general public, and a vast team of experts including technical staff (OSR - e-Services for Life and Health experts), medical experts (pediatricians, psychologists, dieticians), sociologists, nutritionists, designers, teachers, and so on. These individuals are all involved from the early stage of the living lab process and throughout its duration (therefore along the co-creation phase, the exploration phase, the experimentation phase, and finally the evaluation phase). Insights are gathered directly from the users in order to define and implement realistic, useful, desirable and effective artifacts by using a number of tools and techniques.

\section{Methods, Tools and Techniques used in the Living Lab Process}

The co-creation phase of the living lab process can be split into three sub-phases, which focus on the analysis/scoping of the context, the ideation of concepts and the co-design of the services with users. The process starts from an analysis of the selected scenario, in which users' needs, preference and behaviors are examined, alongside a careful research into market segmentations and trends. This first phase produces requirements and specifications that will form the basis for the ideation phase. In this second phase, the needs of end-users are translated into innovative ideas for services, products or digital applications. Innovation can occur substantially in two forms: in an incremental manner (improving something that already exists) or in a disruptive one (creating something that breaks away from what already exists). The direct involvement of the end-user in activities of co-design not only is a more fruitful process through which to spark innovation, but also produces innovative solutions that respond realistically to user needs and problems, thus leading to the creation in this particular case to services which successfully unite users, products and environments for the attainment of users' goals.

The most commonly used tools during the co-creation phase adopted by the City of the Future are focus groups, interviews, brainstorming sessions and questionnaires. All these tools are qualitative and can be used concurrently to build a clear picture of either a market or a targeted user. Another tool that can be used within the co-creation phase of the living lab process is the Lead User Method, developed by Von Hippel [17]. It is a four-stage approach where user needs are explored by involving what Hippel calls "lead users", or expert users with extreme or very evolved requirements. Users can be effectively involved in the innovation process also via co-creation groups. A co-creation group is similar in structure to a focus group, but requires users to actively participate in the creation and development of an idea, be it a product or a service. Idea competition is another spot method where users and stakeholders are asked to submit their innovative ideas to the research team. The ideas presented are to be commented, discussed and voted by other participants or a selected jury. This approach often is a great source of motivation for users, since their peers stimulate them.

The previously mentioned tools are often used on a one-off basis and help to produce very focused and detailed insights. As users are becoming ever more active, informed and empowered, another tool that is very useful on a more continuous basis is consumer or user partnering. This consists of building a long-lasting relationship with a user who on a regular basis meets up with the research team. Crowd sourcing is another way of gaining insight over time. It can involve a group of users or single users, as well as experts or amateurs. A web-based platform or digital application can be created through which users are able to contribute their views and opinions on a given subject. In this way researchers and users co-create value through their continuous interaction towards a common goal. An emerging tool throughout the co-creation phase is serious gaming. Serious games are indeed games (they can be digitally based or physical) but their aim is not only to entertain, but also to train individuals or investigate an issue. Serious games are a dynamic and effective tool to help users access and use new information in an enjoyable manner, providing an enrichment of skills and living experience to its users. They successfully involve users of all social and cultural backgrounds and the "fun" aspect successfully triggers the spontaneous generation of a great number of insights. 
Co-creation is a specific step in the living lab process but often its tools can accompany the entire living lab process, supporting both the phases of experimentation and evaluation. Indeed, the above mentioned tools can be adopted within these phases as ways in which to gather feedback from users, in order to effectively fine-tune the product or service developed and truly making the living lab process user-driven.

In the exploration phase of the living lab process, the main tool used is prototyping. Prototypes can be made in two different manners: in a rough form (called low fidelity prototypes) and in a more finished yet not definite form (called high fidelity). Rough prototyping consists of making quick mock ups, and this exercise is used to simulate products and service components of an idea in order to better explain them to other members of the research team and stakeholders. High fidelity prototypes on the other hand consist of simulating a service's experience by setting up a representation of the service in mind via all its elements in a more finished form. Both approaches are very pragmatic: the first approach allows to de-contextualize problems and issues and confront them with a blank or white slate manner, the second allows for the demonstration and testing of a solution and the drawing up of a set of requirements which will form the basis of the service which will be deployed in the experimentation phase.

Ethnography is a practice adopted from socio-cultural anthropology and is based on a qualitative method where researchers examine the shared and learned patterns of values, behaviors, customers and beliefs in a group of users [18]. Researchers can observe users in their natural environment or in an artificially recreated one, though the prior is preferred because it allows users to feel at ease and therefore manifest more spontaneous attitudes. There are many techniques available, for instance, video ethnography, shadowing, disposable camera studies, day in the life studies, and so forth.

Ethnography is a very useful and commonly used tool during the experimentation phase of the living lab process. Through the study of users interacting with a product, service, or environment in the process of being developed, the research team aims to understand the nature of behaviors between these elements. The insight gathered is fed back into the living lab process, forming the base for the evaluation phase, and allows the product, service or environment to be improved and therefore to respond more successfully to their users, often generating insight beyond the subject researchers initially intend to study.

The City of the Future Living Lab holds participants' security and privacy as a priority. In order to attain the most spontaneous feedback possible, trust has to be built between research team and users, and this is achieved by providing them with clear and easy to understand information on the project they are involved in and the process they are involved in. At the same time, information must be provided on how the facilities and infrastructures can guarantee data confidentiality, integrity, and availability in accordance with Italian national laws and regulations so that users can respond to the methodology and tools in the most spontaneous manner possible (see Figure 2). In order to enhance users' privacy, City of the Future's team performs a risk analysis for every service developed and applies data minimization techniques, digital credentials and pseudonimization mechanisms to all parties involved.

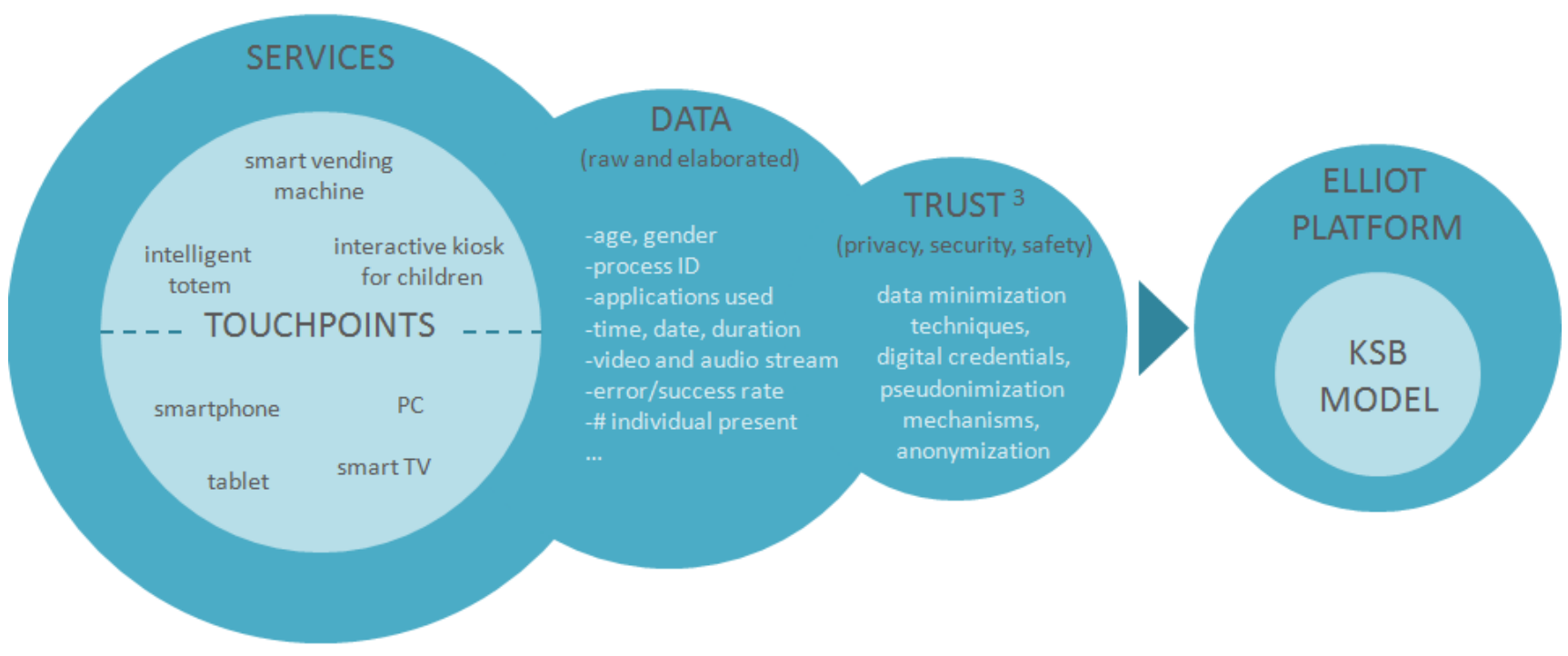

Figure 2. How data flow in City of the Future Living Lab. 
The evaluation phase is the most critical step in the living lab process because it must identify the service's ability to permeate across users and their environment. The evaluation of a service can be viewed through different lenses - for example a business focus aims at understanding whether a service has the capacity of generating revenue over time or if it is sustainable. OSR's interest lies in understanding to what extent the services developed satisfy users' expectations and contribute in producing positive experiences.

In this phase it is common to rely on external experts to draw a series of assessments, such as user experience assessment, human-computer interaction assessment, ergonomic assessment and so on. Another tool often used internally instead is ANVIL 5 [19], software that enables the research team to semantically analyze the way in which users react to a service. The combined results from these different evaluation tools not only provide feedback on the services developed, but also uncover improvements and opportunities in order to help the services tested evolve.

\section{How the theory is put into practice}

In order to represent in a clear and explicative manner the living lab process previously described, examples of a few services that at the moment are being developed by the City of the Future Living Lab will be described.

The co-creation phase of our Mobility and Wayfinding service began with 128 patient and visitor interviews within the Science Park grounds. Each questionnaire had two sections: the first part consisted of about 30 predefined questions with closed answers and had the objective of identifying users' pain points regarding their orientation and movement around the Science Park; the second part consisted of open-questions where the aim was gathering interviewees' personal opinions and experiences related to their mobility as well as suggestions for possible improvements. What emerged from this initial co-creation phase were ten main clusters and relative needs and requirements, as well as a series of ideas for potential service solutions. Three focus groups (one with project stakeholders, one with end users, and one with City of the Future team members) were carried out in order to refine and fine-tune the ideas that emerged from the questionnaires. The result of this co-creation phase is a concept of a way-finding and orientation service that articulates itself across a number of different touchpoints (interactive totem, smartphone and tablet application and website) which are at the moment being experimented with in the Science Park (Figure 3).
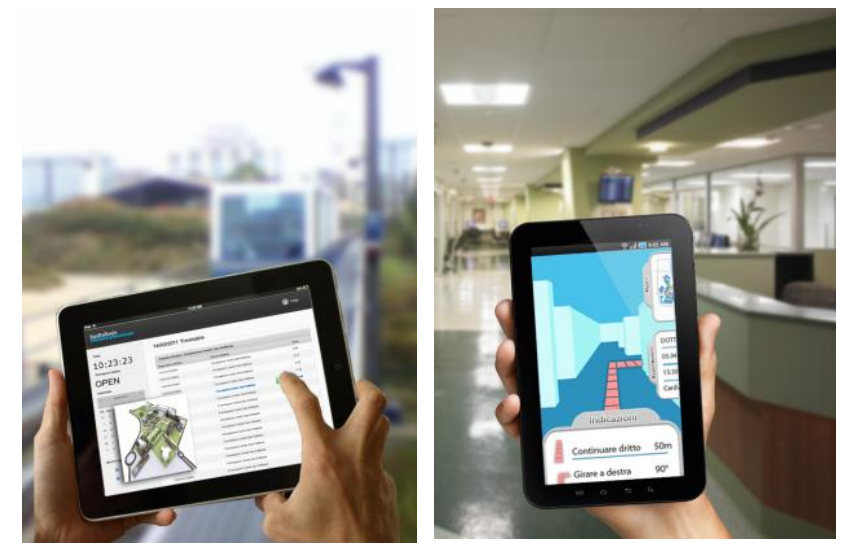

Figure 3. Concepts developed from the co-creation phase of the Mobility and Way-finding service.

The exploration phase of our Totem for Kids service for children in hospital [20], for example, involved the City of the Future team analyzing, testing and modifying a series of software and hardware solutions in order to select the best prototype for an interactive kiosk to be deployed in the pediatric ward OSR for its experimentation phase (Figure 4).
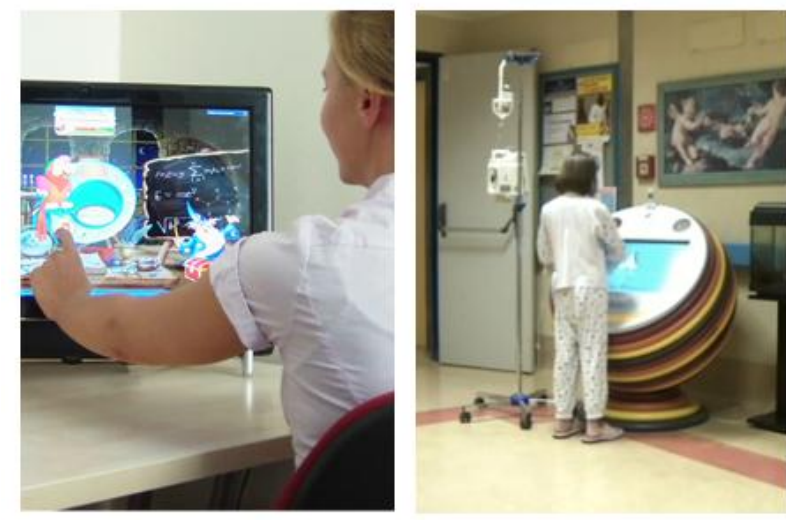

Figure 4. Images illustrating moments from the exploration phase and from the experimentation phase of the Totem for Kids service.

The team involved pediatricians, doctors, child psychologists, nutritionists, designers, and engineers. A first version of the kiosk was placed in the pediatric ward where the hospitalized children and living lab team members worked together to further refine the product and services offered. Children were observed interacting with the kiosk via intensive ethnographic study, whilst its software and a camera positioned on the kiosk gathered relevant information regarding their interactions. A set of specifications emerged and helped to further fine-tune the kiosk before its experimentation phase. In this service's case, the end user has an active role in the exploration phase since the user experience helped tweak the prototype to be used in the experimentation phase. 
The Well-Being on the Go service [21] has recently commenced its experimentation phase. Three vending machines (Figure 5) have been positioned in a newly designed area at the Science Park, and for three months are open to the public. Ethnographic research has already started and involves collecting data from the number of logs, head counting from a set of video cameras, usability questionnaires, a series of thinkaloud exercises, and user shadowing, and will include a final focus group. The insights gathered from the experimentation phase will form the base of the evaluation phase and will drive the fine-tuning of the concept and further development.

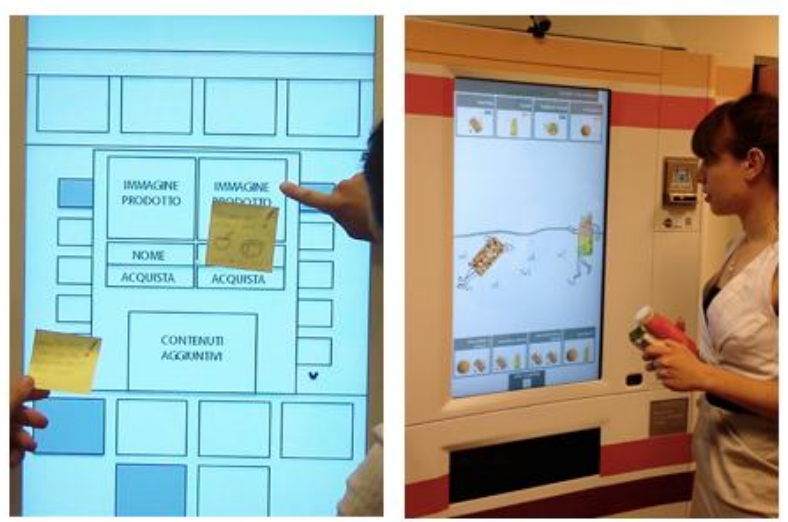

Figure 5. Images illustrating moments from the co-creation phase and from the experimentation phase of the Well-Being on the Go service.

The young age of City of the Future Living Lab, inaugurated in 2011 and awarded ENoLL membership only this year, means that the services previously mentioned as well as other services in development have not yet reached their evaluation phase. Nonetheless, the research team and a number of international partners have recently implemented an experiential analysis platform as an outcome of an EU-funded project entitled ELLIOT (Experiential Living Labs for the Internet of Things) [22]. Within this platform, data are collected via the IoT embedded in the products, services and environments around users (such as cameras, sensors, microphones, etc.), and provide a clear overview of their interactions and attitudes, thus providing researchers the opportunity to further optimize prototypes.

The Living Lab Process is explored and validated by applying a set of Knowledge-Social-Business (KSB) Experience Models [23] to the services tested. Such models, which are specifically designed at the onset of each design process and based upon users' and stakeholders' objectives and expectations, evaluate whether the user and stakeholder objectives and expectations are met or not.

\section{Conclusion}

City of the Future Living Lab is a real and virtual research environment and community that embodies a Smart and Intelligent City. Such a setting provides a unique context for a Living Lab where all actors of a city can actively participate to the innovation process and where all scenarios of everyday life can be accessed and targeted for the development of innovative services and contribute to build Smarter Cities of the Future.

The three different services described in this paper not only help explicate the living lab methodology used by the research team at City of the Future Living Lab, but also introduce the research team's effort to validate the process and desire to find new tools to improve its objectiveness such as the ELLIOT Experiential platform and related KSB model.

A co-creation approach is essential for the ideation and deployment of successful products and services, especially if they are ICT based since the needs and requirements of end users differ according to their level of IT literacy, their age, their demographic details and cultural attitudes. If users are involved from the start of the innovation process, the chances of developing ICT based services that truly respond to user needs and that truly fit their expectations increases since they can freely contribute opinions, ideas, behaviors and preferences.

City of the Future believes that this effective, user-driven process of innovation in a real-life setting will play a vital role also in shaping the implementation of Future Internet technologies. As Smart Cities will embrace the Internet of Content and Knowledge, Internet of People, and the Internet of Services, living labs adopting a concurrently bottom-up and top-down approach achieved via a process of co-creation, will become an ever more important breeding ground for both incremental and especially disruptive innovation. This in turn will lead to the successful deployment of business, societal, economic and environmental change, which will provide the grounds upon which to build Smarter Cities.

\section{References}

[1] A. Caragliu, C. del Bo, and P. Nijkamp, "Smart cities in Europe," VU University Amsterdam, Faculty of Economics, Business Administration and Econometrics, 2009.

Available:

http://ideas.repec.org/p/dgr/vuarem/2009-48.html

[2] R. Florida, The rise of the creative class : And how it's transforming work, leisure, community and everyday life. New York: Basic Books, 2002. 
[3] R. G. Hollands, "Will the real smart city please stand up?," City, vol. 12, no. 3, pp. 303-320, 2008. doi: 10.1080/13604810802479126

[4] H. Schaffers, N. Komninos, M. Pallot, B. Trousse, M. Nilsson, and A. Oliveira, "Smart cities and the future internet: Towards cooperation frameworks for open innovation," in The future internet, J. Domingue, A. Galis, A. Gavras, T. Zahariadis, and D. Lambert, Eds. Berlin; Heidelberg: Springer-Verlag, 2011, pp. 431-446.

[5] A. Coe, G. Paquet, and J. Roy, "E-governance and smart communities a social learning challenge," Social Science Computer Review, vol. 19, no. 1, pp. 80-93, 2001.

doi: $10.1177 / 089443930101900107$

[6] E. Glaeser, "Review of richard florida's the rise of the creative class," Regional Science and Urban Economics, vol. 35, no. 5, pp. 593-596, 2005. doi: 10.1016/j.regsciurbeco.2005.01.005

[7] R. Giffinger, C. Fertner, H. Kramar, R. Kalasek, N. Pichler-Milanović, and E. Meijers, "Smart cities: Ranking of European medium-sized cities," Centre of Regional Science (SRF), Vienna University of Technology, Vienna, Austria, 2007.

Available:

http://www.smart-cities.eu/download/smart_citie s final report.pdf

[8] N. Komninos, "The architecture of intelligent cities: Integrating human, collective and artificial intelligence to enhance knowledge and innovation," in The 2nd IET International Conference on Intelligent Environments (IE O6), Athens, Greece, 2006, pp. 1-13.

Available:

http://link.aip.org/link/IEECPS/v2006/iCP518/pv113/s1\&Agg=doi

[9] P. Droege, Intelligent environments : Spatial aspects of the information revolution. Amsterdam; New York: Elsevier, 1997.

[10] "Ten steps to becoming a smart community," The California Institute for Smart Communities, 2001. Available:

http://www.smartcommunities.org/library_10steps.htm

[11] A. Steventon and S. Wright, Intelligent spaces the application of pervasive ICT. London: Springer, 2006.

[12] N. Komninos, Intelligent cities : Innovation, knowledge systems, and digital spaces. London; New York: Routledge, 2002.

[13] R. Santoro and M. Conte, "Living labs in open innovation functional regions," in The 15th International Conference on Concurrent Enterprising (ICE2009), Leiden, The Netherlands, 2009.

Available:

http://ami-communities.net/pub/bscw.cgi/d441945/Livi ng\%20Labs\%20in\%20Functional\%20Regions\%20-\%20Wh ite\%20Paper.pdf
[14] M. Pallot, Engaging users into research and innovation: The living lab approach as a user centred open innovation ecosystem, Webergence Blog, 2009. [Online].

Available:

http://www.cwe-projects.eu/pub/bscw.cgi/1760838

[15] The european network of living labs: The first step towards a new innovation system, The European Network of Living Labs. [Online].

Available: http://www.openlivinglabs.eu/

[16] S. Vicini, S. Bellini, and A. Sanna, "How to co-create internet of things-enabled services for smarter cities," in The First International Conference on Smart Systems, Devices and Technologies (SMART 2012), Stuttgart, Germany, 2012, pp. 55-61.

Available:

http://www.thinkmind.org/index.php?view=article \&articleid=smart $2012 \quad 2 \quad 50 \quad 40077$

[17] E. von Hippel, "Successful industrial products from customer ideas," Journal of Marketing, vol. 42, no. 1, pp. 39-49, 1978. doi: $\underline{10.2307 / 1250327}$

[18] M. V. Angrosino, Doing ethnographic and observational research. London: Sage Publications, 2008.

[19] ANVIL: The video annotation research tool. [Online].

Available: http://www.anvil-software.de/

[20] S. Vicini, A. Sanna, S. Bellini, and A. Rosi, "An internet of things enabled interactive totem for children in a living lab setting," presented at the 18th International ICE-Conference on Engineering, Technology and Innovation, Munich, Germany, 2012.

[21] S. Vicini, A. Sanna, and S. Bellini, "A living lab for internet of things vending machines," in The impact of virtual, remote, and real logistics labs, vol. 282, D. Uckelmann, B. Scholz-Reiter, I. Rügge, B. Hong, and A. Rizzi, Eds. Berlin; Heidelberg: Springer, 2012, pp. 35-43.

[22] The ELLIOT (experiential living lab for the internet of things) project. [Online].

Available: http://www.elliot-project.eu/

[23] M. Pallot and K. S. Pawar, "A holistic model of user experience for living lab experiential design," presented at the 18th International ICE-Conference on Engineering, Technology and Innovation, Munich, Germany, 2012. 